\title{
Prognostic and predictive value of Phospho-p44/ 42 and PAKT in HER2-positive locally advanced breast cancer patients treated with anthracycline-based neoadjuvant chemotherapy
}

Liang Huang ${ }^{1,2+}$, Tianwen Chen ${ }^{3+}$, Canming Chen ${ }^{1,2^{*}}$, Sheng Chen ${ }^{1,2}$, Yin Liu ${ }^{1,2}$, Jiong Wu $u^{1,2}$ and Zhiming Shao ${ }^{1,2}$

\begin{abstract}
Background: To evaluate the predictive and prognostic value of various molecular factors associated with the Ras/MAPK and PI3K/Akt signaling pathways in HER2-positive locally advanced breast cancer patients treated with anthracycline-based neoadjuvant chemotherapy (NAC).

Methods: A total of 113 patients were recruited in this retrospective study. Core needle biopsies and excision samples were assessed through immunohistochemistry for various biomarkers, including IGF-1R, Phospho-p44/42, Ki67, pAKT, PTEN, p27, and cyclinD1. The changes in these biomarkers after NAC and their predictive and prognostic values were investigated.

Results: Significant decreases in Ki67, Phospho-p44/42, and pAKT expression were observed after treatment ( $30.7 \%$ vs. $18.1 \%, 36.4 \%$ vs. $18.9 \%$, and $35.1 \%$ vs. $16.4 \%$, respectively). The decreases in Phospho-p44/42, pAKT, and Ki67 expression were strongly associated with the response to anthracycline treatment $(P=0.027, P=0.031$, and $P=0.008$, respectively). In a multivariate survival analysis, Phospho-p44/42 expression after neoadjuvant chemotherapy and lymph node status were significant independent prognostic factors of both relapse-free survival and overall survival.

Conclusions: Reductions in Ki-67, Phospho-p44/42, and pAKT expression are related to the clinical response to anthracycline-based NAC in HER2-positive breast cancer patients. High pAKT expression prior to NAC had a better clinical response. Phospho-p44/42 expression and lymph node status after NAC could be useful for determining relapse-free survival and overall survival.
\end{abstract}

Keywords: Breast cancer, HER2/neu, Neoadjuvant chemotherapy, Overall survival, pAKT, Prognostic factors, Phospho-p44/42, Relapse-free survival

\section{Background}

Human epidermal growth factor receptor 2 (HER2) is a tyrosine kinase receptor; up to $25 \%$ of women with early breast cancer are HER2 positive. HER2 is associated with a more aggressive biological behavior, a higher likelihood of recurrence after initial treatment,

\footnotetext{
* Correspondence: fdhlyx@gmail.com

${ }^{\dagger}$ Equal contributors

'Department of Breast Surgery, Fudan University Shanghai Cancer Center/ Cancer Institute, 399 Ling-Ling Road, 200032 Shanghai, People's Republic of China

${ }^{2}$ Department of Oncology, Shanghai Medical College, Fudan University, Shanghai, People's Republic of China

Full list of author information is available at the end of the article
}

and poorer prognosis [1]. Three publications have suggested that HER2 positivity is associated with a relative benefit from anthracycline-containing chemotherapy compared with non-anthracycline-containing regimens, which is in agreement with the results of two metaanalyses [2-6]. Since trastuzumab was approved for use in HER2-positive breast cancer patients, the prognosis of breast cancer patients has improved. When used as a single agent, overall response rates ranging from $15 \%$ to $30 \%$ have been reported [7].

Neoadjuvant chemotherapy (NAC) has been used in locally advanced breast cancer to convert previously unresectable cancer into operable cancer. More recently,

\section{() Biomed Central}


it has been widely administered in primarily operable breast cancer to reduce tumor volume and allow conservative surgery. The complete pathological response rate for patients with HER2-positive tumors is nearly 23\%, but the rate has been shown to increase to $40 \%$ with trastuzumab [8]. The additional use of anthracyclines in combination with trastuzumab is thought to explain the higher complete pathological response rates observed in the GeParQuinto trial [9].

HER2 overexpression may lead to increased receptor homodimerization and heterodimerization, which causes intrinsic receptor tyrosine kinase activity and induces phosphorylation of the intracellular domain. The growth factor receptors utilize several signaling pathways, including the Ras/MAPK pathway, which is important for mitogenic stimulation. They also activate the PI3K/Akt cascade, which has been shown to be important for cell survival and inhibiting apoptosis. The PI3K pathway is downstream of HER2 and is activated to catalyze the phosphorylation of inositol lipids to produce PIP3 from PIP2. PIP3 recruits protein kinases and activates the protein kinase B/AKT pathway. AKT phosphorylation can inhibit cell cycle arrest. The mitogen-activated protein kinase (MAPK) signaling pathway is known to be activated in breast cancer. Extracellular signal-related kinase (ERK), a member of the MAPK pathway, promotes cell proliferation, angiogenesis, cell differentiation, and cell survival.

Insulin-like growth factor receptor-1 (IGFR-1) is a transmembrane heterotetrameric protein. It is the dominant receptor for the IGF family of molecules, and it promotes the oncogenic transformation, growth and survival of cancer cells. IGF-I/II ligand binding induces intracellular tyrosine kinase activity and triggers a cascade of reactions involving signal transduction pathways, including the Ras, Raf, MAPK, and PI3K-AKT pathways. In breast cancer, IGFR-1 expression and activation have been linked to disease progression and poor prognosis $[10,11]$.

To improve the efficacy of treatment in HER2-positive breast cancer patients, it is critical to study the correlation between HER2 signaling pathway activity and the efficacy of adjuvant treatment. Therefore, we initiated a retrospective study to collect serial samples of HER2positive breast cancer for molecular analyses in patients undergoing anthracycline-based neoadjuvant chemotherapy.

\section{Methods}

\section{Ethics statement}

The retrospective study was approved by the Ethics Committee of Shanghai Cancer Center. Written informed consent was obtained from each patient involved in the study.

\section{Patients and clinical samples}

From May 2002 to September 2007, 113 patients with HER2-overexpressing (defined as either $3+$ or $2+$ with confirmed c-erbB2 gene amplification by fluorescence in situ hybridization) stage II to III breast cancer were retrospectively recruited [12]. Core needle biopsy was performed for every patient to confirm the diagnosis of invasive cancer. A complete history, including patient characteristics, clinical and imaging examinations, and pathologic assessments of the morphologic and biologic features of the cancers, was collected. Patients with metastatic diseases, inflammatory breast cancer or male breast cancer were not included in this study. All patients were treated with CEF (cyclophosphamide $600 \mathrm{mg} / \mathrm{m}^{2}$, epirubicin $80 \mathrm{mg} / \mathrm{m}^{2}$ and fluorouracil $500 \mathrm{mg} / \mathrm{m}^{2}, \mathrm{q} 3 \mathrm{w}$ ) or NE (vinorelbine $25 \mathrm{mg} / \mathrm{m}^{2}$ on days 1 and 8 and epirubicin $60 \mathrm{mg} / \mathrm{m}^{2}$ on day $\left.1, \mathrm{q} 3 \mathrm{w}\right)$. Following completion of neoadjuvant treatment, all patients underwent breast surgery. For adjuvant chemotherapy, $74.3 \%$ of cases had an anthracycline-based regimen, and $10.6 \%$ of cases had a paclitaxel regimen; two patients received trastuzumab treatment for 1 year. Other standard therapies, including radiation therapy and endocrine therapy, were administered at the discretion of the treating clinician following NCCN guidelines. All patients were followed-up every 3 months for the first year and then every 6 months until death.

\section{Assessment of the response to neoadjuvant chemotherapy}

All surgical specimens were submitted for pathological evaluation. A complete pathological response was defined as no residual invasive carcinoma in the breast or lymph nodes. The clinical stage and size of the primary tumor measured by MRI or ultrasonography were recorded before treatment. The primary tumor was measured as the product of its greatest diameter. The clinical response was evaluated at each cycle of chemotherapy and prior to definitive surgery on day 21 of the last cycle of chemotherapy as the product of the primary tumor diameters and the axillary clinical status and classified as a complete response, partial response, stable disease, or progressive disease according to the solid tumors criteria (RECIST 1.1).

\section{Immunochemistry}

Immunohistochemistry was performed on deparaffinized sections of all core needle biopsies and surgical tumor samples. Antibodies for P27, Phospho-p44/42 and pAKT required antigen retrieval in a pressure cooker. Briefly, after antigen retrieval, endogenous peroxidases and biotin were blocked with $3 \%$ hydrogen peroxide and an Avidin-Biotin Blocking Kit (Vector, CA), respectively. This was followed by incubation with the primary 
Table 1 Clinical characteristics of HER2-positive breast cancer patients and the univariate analysis of predictive biomarkers of the response to anthracyclines

\begin{tabular}{|c|c|c|c|c|c|c|c|}
\hline \multirow[t]{2}{*}{ Factors } & \multirow{2}{*}{$\begin{array}{l}\text { Number of } \\
\text { patients (\%) }\end{array}$} & \multicolumn{3}{|l|}{ Clinical response } & \multicolumn{3}{|c|}{ Pathological response } \\
\hline & & $\begin{array}{l}\text { Stable disease }+ \\
\text { progressive disease }\end{array}$ & $\begin{array}{l}\text { Partial response }+ \\
\text { complete response }\end{array}$ & $P$ & $\begin{array}{l}\text { Complete } \\
\text { pathological } \\
\text { response }\end{array}$ & $\begin{array}{l}\text { Incomplete } \\
\text { pathological } \\
\text { response }\end{array}$ & $P$ \\
\hline \multicolumn{8}{|l|}{ Age } \\
\hline 45 years & $34(30 \%)$ & 10 & 24 & 0.975 & 3 & 31 & 0.450 \\
\hline$\geq 45$ years & $79(70 \%)$ & 23 & 56 & & 11 & 68 & \\
\hline \multicolumn{8}{|l|}{ Menopausal status } \\
\hline Postmenopausal & $69(61 \%)$ & 20 & 49 & 0.949 & 7 & 62 & 0.364 \\
\hline Premenopausal & $44(39 \%)$ & 13 & 31 & & 7 & 37 & \\
\hline \multicolumn{8}{|l|}{ Regimen } \\
\hline CEF & $55(49 \%)$ & 15 & 40 & 0.660 & 9 & 46 & 0.212 \\
\hline $\mathrm{NE}$ & $58(51 \%)$ & 18 & 40 & & 5 & 53 & \\
\hline \multicolumn{8}{|l|}{ Tumor size } \\
\hline$\leq 5 \mathrm{~cm}$ & $46(41 \%)$ & 21 & 25 & 0.001 & 4 & 42 & 0.323 \\
\hline$>5 \mathrm{~cm}$ & $67(59 \%)$ & 12 & 55 & & 10 & 57 & \\
\hline \multicolumn{8}{|c|}{ Lymph node status } \\
\hline 0 & $43(38 \%)$ & - & - & - & - & - & - \\
\hline 1 to 3 & $31(27 \%)$ & - & - & - & - & - & - \\
\hline 4 to 9 & $25(22 \%)$ & - & - & - & - & - & - \\
\hline$\geq 10$ & $14(13 \%)$ & - & - & - & - & - & - \\
\hline \multicolumn{8}{|c|}{ Pre-estrogen receptor } \\
\hline Negative & 78 (69\%) & 21 & 57 & 0.426 & 10 & 68 & 0.835 \\
\hline Positive & $35(31 \%)$ & 12 & 23 & & 4 & 31 & \\
\hline \multicolumn{8}{|c|}{ Pre-progesterone receptor } \\
\hline Negative & $83(73 \%)$ & 24 & 59 & 0.911 & 9 & 74 & 0.518 \\
\hline Positive & $30(27 \%)$ & 9 & 21 & & 5 & 25 & \\
\hline \multicolumn{8}{|l|}{ Pre-pMAPK } \\
\hline Negative & $34(30 \%)$ & 13 & 21 & 0.166 & 8 & 26 & 0.855 \\
\hline Positive & $79(70 \%)$ & 20 & 59 & & 6 & 73 & \\
\hline \multicolumn{8}{|l|}{ Pre-pAKT } \\
\hline Negative & $30(27 \%)$ & 14 & 16 & 0.014 & 4 & 26 & 0.855 \\
\hline Positive & $83(73 \%)$ & 19 & 64 & & 10 & 73 & \\
\hline \multicolumn{8}{|l|}{ Pre-PTEN } \\
\hline Negative & $40(35 \%)$ & 13 & 27 & 0.568 & 5 & 35 & 0.979 \\
\hline Positive & $73(65 \%)$ & 20 & 53 & & 9 & 64 & \\
\hline \multicolumn{8}{|l|}{ Pre-P27 } \\
\hline Negative & 35 (31\%) & 15 & 20 & 0.432 & 5 & 40 & 0.737 \\
\hline Positive & 68 (69\%) & 18 & 50 & & 9 & 59 & \\
\hline \multicolumn{8}{|l|}{ Pre-IGF-1R } \\
\hline Negative & 47 (42\%) & 12 & 35 & 0.469 & 5 & 42 & 0.634 \\
\hline Positive & 66 (58\%) & 21 & 45 & & 9 & 57 & \\
\hline \multicolumn{8}{|l|}{ Pre-cyclinD1 } \\
\hline Negative & 42 (37\%) & 14 & 28 & 0.458 & 4 & 38 & 0.477 \\
\hline
\end{tabular}


Table 1 Clinical characteristics of HER2-positive breast cancer patients and the univariate analysis of predictive biomarkers of the response to anthracyclines (Continued)

\begin{tabular}{lccccc}
\hline Positive & $71(63 \%)$ & 19 & 52 & 10 & 61 \\
Pre-Ki67 & & & & 0.298 & 2 \\
Negative & $43(38 \%)$ & 15 & 28 & 12 & 41 \\
Positive & $70(62 \%)$ & 18 & 52 & 58 & 0.076 \\
\hline
\end{tabular}

IGF-1R, insulin-like growth factor 1 receptor; pAKT, phosphorylated AkT; pMAPK, phosphorylated mitogen-activated protein kinase.

antibody for 60 minutes at room temperature, the appropriate secondary antibody (Dako), labeled streptavidin-horseradish-peroxidase (Dako), DAB chromogen, and $0.2 \%$ osmium tetroxide (Sigma Chemicals, St Louis, $\mathrm{MO})$, followed by counterstaining with light hematoxylin. Appropriate positive controls for each antibody and negative controls using species-matched immunoglobulin to replace the primary antibody were run with each batch. Positive tumor cells were quantified by evaluating at least 1,000 cells and expressed as percentages. Samples were evaluated by two trained pathologists (Dr. Zou, Dr. Li) who were blinded to the patient background and clinical outcome. If the difference between the two results was more than $10 \%$, a third pathologist (Dr. Zhou) was consulted.

The cut-off for estrogen receptor (clone 1D5, Dako) and progesterone receptor (clone PgR 636, Dako) positivity was $1 \%$ of tumor cells with positive nuclear staining. For Phospho-p44/42 (clone 20G11, Cell Signaling) and pAKT (clone 736E11, Cell Signaling), the cut-off for positive expression was $20 \%$ of cells with nuclear and cytoplasmic expression [13]. The cut-off for Ki67 (clone MIB-1, Dako) positivity was $14 \%$ of tumor cells with positive nuclear staining. The cut-off for other markers was 10\%, including nuclear staining for P27 (clone SX53G8, Dako) and cyclinD1 (clone EP12, Dako), membranous and cytoplasmic staining for IGF-1R (clone 3027, Cell Signaling), and cytoplasmic and nuclear staining for PTEN (clone 6H2.1, Dako) [14-16]. The reduction between the pre-NAC average percentage and
post-NAC average percentage was defined as the reduction cut-off for Ki67, pAKT, and Phospho-p44/42 (13\%, $19 \%$, and $18 \%$, respectively).

\section{Statistical analysis}

Descriptive statistics were calculated to summarize patient characteristics, tumor size, and the biomarker levels in the core needle biopsies and surgical tumor samples. Biomarker expression levels in pre- and postchemotherapy tumor samples were compared using a paired $t$ test. The initial biomarker levels were compared between responders and non-responders using the chisquare test. Fisher's exact test was performed when necessary. A simultaneous analysis of the biomarkers that were significantly predictive of tumor response in the univariate analysis was performed using a multivariate logistic regression.

Survival results were last updated in September 2012. Relapse-free survival was defined as the elapsed time between the date of first diagnosis and the date of first relapse. Overall survival was calculated from the date of diagnosis to the date of death or last follow-up. Patients without events or death were censored at the last follow-up. Survival curves were established according to the Kaplan-Meier method. The log-rank test was used for univariate comparison of survival endpoints. A Cox regression was used to assess the relative influence of prognostic factors on relapse-free survival and overall survival. All tests were considered significant at a two-

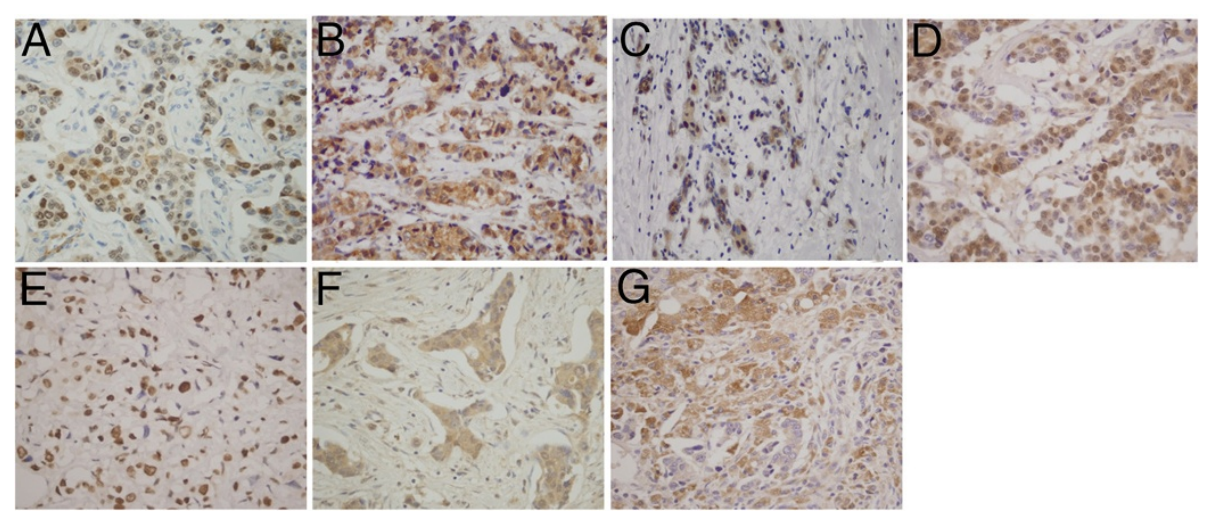

Figure 1 Positive immunohistochemical expression: (A) Ki67, (B) Phospho-p44/42, (C) pAKT, (D) p27, (E) PTEN, (F) IGF-1R, (G) cyclinD1. 
Table 2 Univariate analysis of relapse-free survival and overall survival

\begin{tabular}{|c|c|c|c|c|c|c|c|c|c|}
\hline \multirow[t]{2}{*}{ Factor } & \multicolumn{2}{|c|}{ Relapse-free survival } & \multicolumn{2}{|c|}{ Overall survival } & \multirow[t]{2}{*}{ Factor } & \multicolumn{2}{|c|}{ Relapse-free survival } & \multicolumn{2}{|c|}{ Overall survival } \\
\hline & $P$ & $\begin{array}{c}\text { Hazard ratio } \\
(95 \% \\
\text { confidence } \\
\text { interval) }\end{array}$ & $P$ & $\begin{array}{c}\text { Hazard ratio } \\
(95 \% \\
\text { confidence } \\
\text { interval) }\end{array}$ & & $P$ & $\begin{array}{c}\text { Hazard ratio } \\
(95 \% \\
\text { confidence } \\
\text { interval) }\end{array}$ & $P$ & $\begin{array}{c}\text { Hazard ratio } \\
(95 \% \\
\text { confidence } \\
\text { interval) }\end{array}$ \\
\hline \multicolumn{10}{|l|}{ Age } \\
\hline$<45 y$ vs. $\geq 45 y$ & 0.724 & 1.2 (0.5 to 2.7$)$ & 0.256 & 1.0 (0.9 to 1.0$)$ & & & & & \\
\hline \multicolumn{10}{|l|}{ Menopausal status } \\
\hline $\begin{array}{l}\text { Premenopausal vs. } \\
\text { Postmenopausal }\end{array}$ & 0.663 & $0.9(0.5$ to 1.5$)$ & 0.822 & 1.0 (0.6 to 2.0$)$ & & & & & \\
\hline \multicolumn{10}{|l|}{ Regimen } \\
\hline CEF vs. NE & 0.479 & 1.2 (0.7 to 2.0$)$ & 0.568 & 1.2 (0.6 to 2.2 ) & & & & & \\
\hline \multicolumn{10}{|l|}{ Tumor size } \\
\hline$\leq 5 \mathrm{~cm}$ vs. $>5 \mathrm{~cm}$ & 0.784 & 1.1 (0.6 to 2.0 ) & 0.456 & 1.3 (0.6 to 2.8 ) & & & & & \\
\hline \multicolumn{10}{|l|}{ Lymph node status } \\
\hline \multicolumn{10}{|l|}{ Negative } \\
\hline 1 to 3 nodes + & 0.007 & 2.7 (1.3 to 5.6$)$ & 0.012 & 4.3 (1.4 to 13.3 ) & & & & & \\
\hline 4 to 9 nodes + & $<0.001$ & 4.6 (2.2 to 9.5$)$ & 0.001 & $7.2(2.4$ to 21.9$)$ & & & & & \\
\hline$\geq 10$ nodes + & $<0.001$ & 6.8 (3.0 to 15.9 ) & $<0.001$ & 13.7 (4.3 to 44.4$)$ & & & & & \\
\hline $\begin{array}{l}\text { Pre-estrogen } \\
\text { receptor }\end{array}$ & & & & & $\begin{array}{l}\text { Post-estrogen } \\
\text { receptor }\end{array}$ & & & & \\
\hline $\begin{array}{l}\text { Negative vs. } \\
\text { positive }\end{array}$ & 0.252 & 1.4 (0.8 to 2.3 ) & 0.620 & 1.2 (0.6 to 2.2 ) & $\begin{array}{l}\text { Negative vs. } \\
\text { positive }\end{array}$ & 1.000 & $1.0(0.5$ to 1.8$)$ & 0.540 & $0.8(0.4$ to 1.7$)$ \\
\hline $\begin{array}{l}\text { Pre-progesterone } \\
\text { receptor }\end{array}$ & & & & & $\begin{array}{l}\text { Post-progesterone } \\
\text { receptor }\end{array}$ & & & & \\
\hline $\begin{array}{l}\text { Negative vs. } \\
\text { positive }\end{array}$ & 0.724 & 0.9 (0.5 to 1.6$)$ & 0.334 & 0.7 (0.3 to 1.5$)$ & $\begin{array}{l}\text { Negative vs. } \\
\text { positive }\end{array}$ & 0.841 & $1.0(0.6$ to 2.0$)$ & 0.754 & 0.9 (0.4 to 2.0) \\
\hline Pre-Ki67 & & & & & Post-Ki67 & & & & \\
\hline $\begin{array}{l}\text { Negative vs. } \\
\text { positive }\end{array}$ & 0.840 & 1.1 (0.6 to 1.8$)$ & 0.647 & 0.9 (0.5 to 1.6$)$ & $\begin{array}{l}\text { Negative vs. } \\
\text { positive }\end{array}$ & 0.260 & 1.4 (0.8 to 2.3$)$ & 0.434 & 1.3 (0.7 to 2.4) \\
\hline Pre-pMAPK & & & & & Post-pMAPK & & & & \\
\hline $\begin{array}{l}\text { Negative vs. } \\
\text { positive }\end{array}$ & 0.174 & 0.7 (0.4 to 1.2 ) & 0.788 & 1.1 (0.6 to 2.2 ) & $\begin{array}{l}\text { Negative vs. } \\
\text { positive }\end{array}$ & 0.019 & 2.0 (1.1 to 3.5$)$ & $<0.001$ & 3.7 (1.9 to 7.0$)$ \\
\hline Pre-pAKT & & & & & Post-pAKT & & & & \\
\hline $\begin{array}{l}\text { Negative vs. } \\
\text { positive }\end{array}$ & 0.224 & 0.7 (0.4 to 1.2$)$ & 0.104 & 0.6 (0.3 to 1.1$)$ & $\begin{array}{l}\text { Negative vs. } \\
\text { positive }\end{array}$ & 0.551 & 0.8 (0.5 to 1.5$)$ & 0.548 & 0.8 (0.4 to 1.7$)$ \\
\hline Pre-PTEN & & & & & Post-PTEN & & & & \\
\hline $\begin{array}{l}\text { Negative vs. } \\
\text { positive }\end{array}$ & 0.450 & 0.8 (0.5 to 1.4$)$ & 0.538 & 0.8 (0.4 to 1.5$)$ & $\begin{array}{l}\text { Negative vs. } \\
\text { positive }\end{array}$ & 0.622 & 0.9 (0.5 to 1.6$)$ & 0.571 & 1.3 (0.6 to 2.7) \\
\hline Pre-P27 & & & & & Post-P27 & & & & \\
\hline $\begin{array}{l}\text { Negative vs. } \\
\text { positive }\end{array}$ & 0.929 & 1.0 (0.6 to 1.6$)$ & 0.439 & 0.8 (0.4 to 1.5$)$ & $\begin{array}{l}\text { Negative vs. } \\
\text { positive }\end{array}$ & 0.220 & 1.4 (0.8 to 2.5$)$ & 0.317 & 1.4 (0.7 to 2.9$)$ \\
\hline Pre-IGF-1R & & & & & Post-IGF-1R & & & & \\
\hline $\begin{array}{l}\text { Negative vs. } \\
\text { positive }\end{array}$ & 0.728 & 1.1 (0.7 to 1.8$)$ & 0.874 & 1.1 (0.6 to 2.0) & $\begin{array}{l}\text { Negative vs. } \\
\text { positive }\end{array}$ & 0.388 & 0.8 (0.5 to 1.3$)$ & 0.760 & 1.1 (0.6 to 2.2 ) \\
\hline Pre-cyclinD1 & & & & & Post-cyclinD1 & & & & \\
\hline $\begin{array}{l}\text { Negative vs. } \\
\text { positive }\end{array}$ & 0.606 & $1.2(0.7$ to 2.0$)$ & 0.814 & $1.1(0.6$ to 2.1$)$ & $\begin{array}{l}\text { Negative vs. } \\
\text { positive }\end{array}$ & 0.602 & 1.2 (0.7 to 2.1 ) & 0.912 & $1.0(0.5$ to 2.1$)$ \\
\hline
\end{tabular}

IGF-1R, insulin-like growth factor 1 receptor; pAKT, phosphorylated AKT; PMAPK, phosphorylated mitogen-activated protein kinase. 

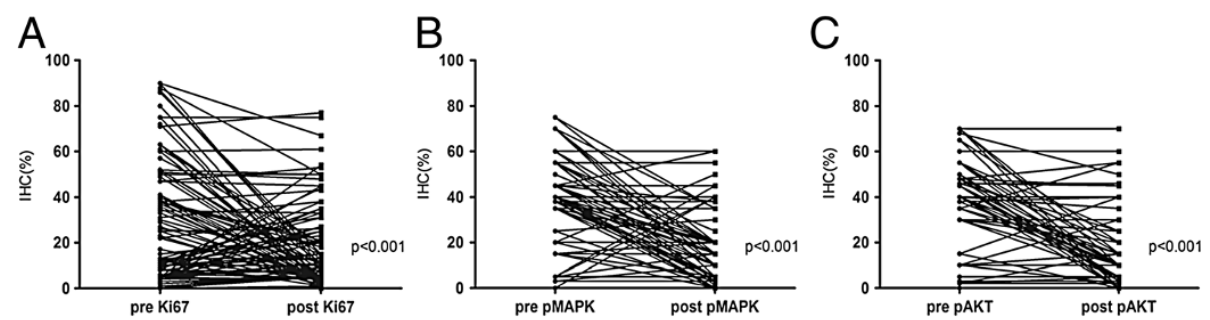

Figure 2 Ki67, Phospho-p44/42 and pAKT expression were significantly decreased after anthracycline treatment. (A) Ki67, (B) Phospho-p44/42, (C) pAKT.

sided $P<0.05$. All analyses were performed using SPSS 17.0 (SPSS, Chicago, IL).

\section{Results}

\section{Clinical characteristics and responses to NAC}

A total of 113 HER2-positive breast cancer patients were recruited in this retrospective study. The average age of patients at diagnosis was 49 (range 26 to 78 ) years; 69 patients were premenopausal at presentation. There were 67 patients with a baseline tumor size greater than $5 \mathrm{~cm}$. The CEF regimen was given to 55 patients, and the other patients received the NE regimen. The mean number of NAC cycles was 3.52 (range 1 to 8 ), and the objective response (complete response + partial response) and non-response rates (progressive disease + stable disease) were $70.8 \%$ and $29.2 \%$, respectively. Eight patients underwent breast-conserving surgery. The clinical characteristics of these patients are shown in Table 1.

\section{Changes in biomarker expression after NAC}

The expressions of various biomarkers (in Figure 1) before and after NAC were compared in 99 patients who did not achieve complete pathological response after NAC. A paired $t$ test analysis found no significant changes in p27, PTEN, IGF-1R, or cyclinD1 expression ( $15.7 \%$ vs. $16.5 \%, 17.0 \%$ vs. $18.3 \%, 49.0 \%$ vs. $51.0 \%$, and $18.2 \%$ vs. $16.9 \%$, respectively). A significant decrease in Ki67, Phospho-p44/42, and pAKT expression was observed after treatment ( $30.7 \%$ vs. $18.1 \%, 36.4 \%$ vs. $18.9 \%$, and $35.1 \%$ vs. $16.4 \%$, respectively). We defined positivestaining tumor cells decreasing by more than the cut-off value as positive decrease in biomarker expression. The details are shown in Table 2. Ki67, Phospho-p44/42, and pAKT expression were all significantly decreased after anthracycline-based neoadjuvant chemotherapy, as shown in Figure 2.

\section{Predictors and response to NAC}

Biomarkers and clinical characteristics were examined to investigate their value in predicting the NAC response (Table 2). Univariate analysis demonstrated that tumor size and pre-pAKT were predictive factors of the response to anthracyclines $(P=0.001$ and $P=0.014$, respectively). Multivariate analysis demonstrated that primary tumor size and pAKT expression remained independent predictive factors of the clinical response to anthracycline-based NAC ( $P=0.012$ and $P=0.031$, respectively). However, no biomarker could predict a pathologic complete response. We also found that the clinical response was coincident with decreased biomarker expression, including Ki67, pAKT, and Phosphop44/42 ( $P=0.001, P=0.002$, and $P=0.007$, respectively), as shown in Figure 3.

\section{Prognostic markers}

The median follow-up time was 60 months (ranging from 14 to 123 months). The overall 5-year relapse-free survival was $50.4 \%$, and the overall survival was $72.6 \%$. A univariate analysis (Table 2) demonstrated that the number of positive lymph nodes and post-Phospho-p44/42 expression were prognostic factors for relapse-free survival. In the multivariate analysis, the number of positive
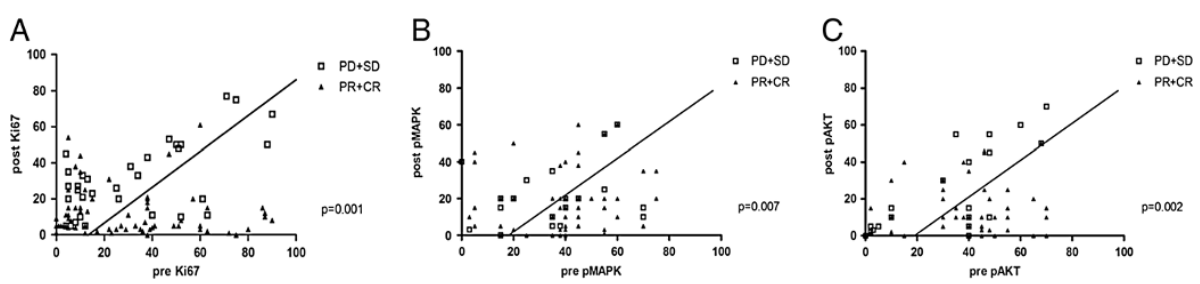

Figure 3 Correlation between pretreatment and post-treatment markers and the pathological response. Values below the line indicate the percentage decrease compared to the cut-off value. (A) Ki67, (B) Phospho-p44/42, (C) pAKT. 
lymph nodes (hazard ratio, 2.0; 95\% confidence interval, 1.6 to $2.6 ; P<0.001$ ) and post-Phospho-p44/42 expression (hazard ratio, 2.3; 95\% confidence interval 1.3 to 4.1; $P<0.001)$ remained significantly independent prognostic factors. In the univariate analysis (Table 2), lymph node status $(P<0.001)$ and post-Phospho-p44/42 expression $(P=0.019)$ showed clear associations with overall survival. In the multivariate analysis, lymph node status (hazard ratio, 2.3; 95\% confidence interval, 1.7 to 3.3; $P<0.001$ ) and post-Phospho-p44/42 expression (hazard ratio, 4.3; $95 \%$ confidence interval, 2.2 to $8.4 ; P<0.001$ ) were also significant predictors of overall survival. Representative survival curves are shown in Figure 4.

\section{Discussion}

To our knowledge, this is the largest analysis of PI3K-Akt and MAPK pathway activation in HER2overexpressing breast cancer patients who received an anthracycline-based neoadjuvant chemotherapy regimen without trastuzumab.

Owing to its aggressive nature and poor prognosis, a number of preclinical and clinical studies have focused on the HER2-positive subtype. The use of anthracyclines in neoadjuvant treatments for HER2-positive breast cancer in addition to trastuzumab is still controversial [17].

HER2 signaling activates pathways (PI3K/Akt and Ras/MAPK) regulating cell cycle progression and cell proliferation. In HER2-overexpressing MBC group, Gori (et al. found that Phospho-p44/42 and pAKT were not associated with the clinical outcome, although low Phospho-p44/42 expression showed a trend for association with a longer overall survival [18]. In our study, the pre-pAKT and pre-Phospho-p44/42 expression rates were high, and this finding has been confirmed by other recent studies [19-21]. The results indicate that the Ras/MAPK and PI3K/Akt pathways are universally active in locally advanced breast cancer with HER2 overexpression. However, the PI3K/Akt and Ras/MAPK pathways have been related to resistance to doxorubicin and paclitaxel in breast cancer cells [22,23]. The level of pre-pAKT expression has been shown to have a significant correlation with the objective response rates to anthracycline treatment. It is possible that Akt isoforms have a distinct impact on the cellular resistance to a given drug and, in fact, Akt activity does not confer equal resistance to different chemotherapeutic agents. For example, the overexpression of constitutively active Akt isoforms in HeLa cells has been shown to induce isoform-specific sensitivity to doxorubicin [24]. The role of pAKT in the neoadjuvant setting is still controversial, owing to limited investigations, even in large clinical trials. However, decreases in Phospho-p44/42 and pAKT expression are related to the response to anthracyclines. Higher levels of active MAPK may have aggressive
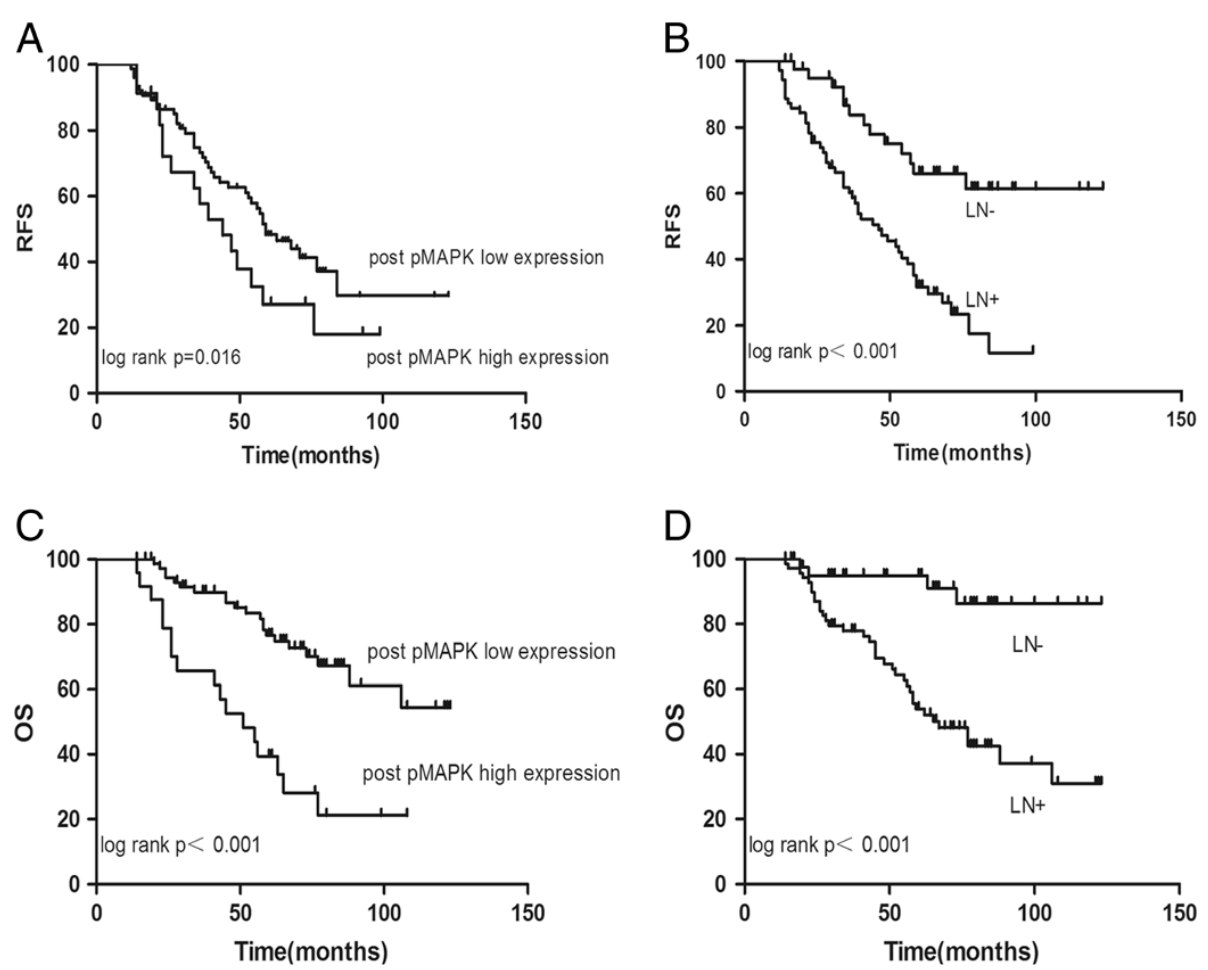

Figure 4 Kaplan-Meier curves. Curves for relapse-free survival according to (A) post-Phospho-p44/42 and (B) lymph node status. Curves for overall survival according to (C) post-Phospho-p44/42 and (D) lymph node status. 
biological behavior, which has been found to be associated with lymph node metastasis [25]. In the TNBC subgroup, high ERK protein expression levels and shorter survival times have been observed [26]. After anthracycline-based adjuvant treatment, a higher score was significantly associated with poorer survival following relapse compared to a lower expression score among patients with MAPK overexpression [21].

Furthermore, few studies have presented precise values for pAKT and Phospho-p44/42 in neoadjuvant chemotherapy. In our study, low Phospho-p44/42 expression after neoadjuvant chemotherapy was a strong prognostic factor for these patients. Patients with high postPhospho-p44/42 expression had a higher recurrence rate (up to $68 \%$ ) in the first 5 years, while patients with low post-Phospho-p44/42 expression had a lower recurrence rate $(45 \%)$, and the survival difference between the two groups was highly significant. It is possible that decreased pAKT and Phospho-p44/42 expression promotes tumor apoptosis and inhibits tumor proliferation, resulting in a survival benefit for HER2-positive breast cancer patients treated with anthracyclines. It is also possible that topoisomerase II $\alpha$ expression is regulated by Ras pathways and tumor proliferation status. The activation of the Ras/Raf/MAPK pathway has been shown to be involved in the induction of MRP-1 activity and topoisomerase II $\alpha$ downregulation, which are the main mechanisms of anthracycline resistance [27].

Higher levels of the proliferation marker Ki67 are associated with poorer survival in breast cancer patients, but we found no prognostic value for pre-NAC Ki67, post-NAC Ki67, or the Ki67 fold change. Other studies have reached controversial conclusions, and it is therefore difficult to choose reasonable predictive and prognostic factors among pre-NAC Ki67, post-NAC Ki67, and Ki67 reduction [14,28-30].

This study has limitations common to all retrospective analyses, and it lacked a control group, such as patients treated with trastuzumab-containing NAC. However, based on results of big clinical trials, such as HERA, BCIRG 006, NCCTG N9831, and NSABP B-31, trastuzumab was approved for adjuvant chemotherapy after 2005 . In our study, $71 \%$ patients were treated before 2005 when most patients did not receive trastuzumab in developing countries. Additionally, the number of patients was small. However, the scientific and clinical community must establish and evaluate these biomarkers and standardize cut-off levels. Although a measurement of topoisomerase II- $\alpha$ amplification was not within the scope of this study, a possible explanation for our findings may be that other confounding molecular factors are involved in the mechanism of the anthracycline response in HER2-positive patients.

\section{Conclusions}

In HER2-positive breast cancer patients treated with anthracyclines, the expression of pAKT, Phospho-p44/ 42, and Ki67 decreased significantly after treatment. Furthermore, patients with high pAKT expression before NAC had higher objective response rates to anthracyclines. The results of our study demonstrate that Phospho-p44/42 expression after neoadjuvant chemotherapy is a strong predictor of outcome. It will be necessary and valuable to further evaluate potential therapeutic targets of the PI3K and MEK signaling pathways in HER2-positive breast cancer patients.

\section{Abbreviations}

ERK: Extracellular signal-related kinase; HER2: Human epidermal growth factor Receptor 2; IGF-1R: Insulin-like growth factor 1 receptor; MAPK: Mitogenactivated protein kinase; NAC: Neoadjuvant chemotherapy; PAKT: Phosphoprotein kinase B; Phospho-p44/42: Phospho-mitogen-activated protein kinase; PMAPK: Phosphorylated mitogen-activated protein kinase.

\section{Competing interests}

All authors declare that they have no potential conflict of interest.

\section{Authors' contributions}

$\mathrm{LH}$ and T-WC have made substantial contributions to the conception and design of the study, and the acquisition of data. SC and YL analyzed and interpreted the data. JW and Z-MS revised the manuscript critically for important intellectual content. C-MC gave final approval of the version to be published. All authors read and approved the final manuscript.

\section{Acknowledgements}

This research is supported by Multidiscipline Comprehensive Treatment Cooperation Group Foundation of Fudan University Cancer Hospital, Shanghai, China (DXK200801), the Key Clinical Program of the Ministry of Health (2010 to 2012). The funders had no role in study design, data collection and analysis, decision to publish, or preparation of the manuscript.

\section{Author details}

'Department of Breast Surgery, Fudan University Shanghai Cancer Center/ Cancer Institute, 399 Ling-Ling Road, 200032 Shanghai, People's Republic of China. ${ }^{2}$ Department of Oncology, Shanghai Medical College, Fudan

University, Shanghai, People's Republic of China. ${ }^{3}$ Department of Thyroid and Breast Surgery, Affiliated Nanshan Hospital of Guangdong Medical College,

Shenzhen, People's Republic of China.

Received: 23 April 2013 Accepted: 9 November 2013

Published: 30 November 2013

\section{References}

1. Slamon DJ, Clark GM, Wong SG, Levin WJ, Ullrich A, McGuire WL: Human breast cancer: correlation of relapse and survival with amplification of the HER-2/neu oncogene. Science 1987, 235:177-182.

2. De Placido S, Perrone F, Carlomagno C, Morabito A, Pagliarulo C, Lauria R, Marinelli A, De Laurentiis M, Varriale E, Petrella G, Gallo C, Bianco AR: CMF vs alternating CMF/EV in the adjuvant treatment of operable breast cancer. A single centre randomised clinical trial (Naples GUN-3 study). Br J Cancer 1995, 71:1283-1287.

3. Pritchard KI, Shepherd LE, O'Malley FP, Andrulis IL, Tu D, Bramwell VH, Levine MN: HER2 and responsiveness of breast cancer to adjuvant chemotherapy. N Engl J Med 2006, 354:2103-2111.

4. Paik S, Bryant J, Park C, Fisher B, Tan-Chiu E, Hyams D, Fisher ER, Lippman ME, Wickerham DL: Wolmark N: erbB-2 and response to doxorubicin in patients with axillary lymph node-positive, hormone receptor-negative breast cancer. J Natl Cancer Inst 1998, 90:1361-1370.

5. Dhesy-Thind B, Pritchard Kl, Messersmith H, O'Malley F, Elavathil L, Trudeau M: HER2/neu in systemic therapy for women with breast cancer: a systematic review. Breast Cancer Res Treat 2008, 109:209-229. 
6. Gennari A, Sormani MP, Pronzato P, Puntoni M, Colozza M, Pfeffer U, Bruzzi P HER2 status and efficacy of adjuvant anthracyclines in early breast cancer: a pooled analysis of randomized trials. J Natl Cancer Inst 2008 100:14-20.

7. Montemurro F, Aglietta M: Incorporating trastuzumab into the neoadjuvant treatment of HER2-overexpressing breast cancer. Clin Breast Cancer 2005, 6:77-80.

8. von Minckwitz G, Untch M, Blohmer JU, Costa SD, Eidtmann H, Fasching PA, Gerber B, Eiermann W, Hilfrich J, Huober J, Jackisch C, Kaufmann M, Konecny GE, Denkert C, Nekljudova V, Mehta K, Loibl S: Definition and impact of pathologic complete response on prognosis after neoadjuvant chemotherapy in various intrinsic breast cancer subtypes. J Clin Oncol 2012, 30:1796-1804

9. Untch M, Loibl S, Bischoff J, Eidtmann H, Kaufmann M, Blohmer JU, Hilfrich J, Strumberg D, Fasching PA, Kreienberg R, Tesch H, Hanusch C, Gerber B, Rezai M, Jackisch C, Huober J, Kühn T, Nekljudova V, von Minckwitz G, German Breast Group (GBG), Arbeitsgemeinschaft Gynäkologische Onkologie-Breast (AGO-B) Study group: Lapatinib versus trastuzumab in combination with neoadjuvant anthracycline-taxane-based chemotherapy (GeparQuinto, GBG 44): a randomised phase 3 trial. Lancet Oncol 2012, 13:135-144.

10. Creighton CJ, Casa A, Lazard Z, Huang S, Tsimelzon A, Hilsenbeck SG, Osborne CK, Lee AV: Insulin-like growth factor-I activates gene transcription programs strongly associated with poor breast cancer prognosis. J Clin Oncol 2008, 26:4078-4085.

11. Turner BC, Haffty BG, Narayanan L, Yuan J, Havre PA, Gumbs AA, Kaplan L, Burgaud JL, Carter D, Baserga R, Glazer PM: Insulin-like growth factor-I receptor overexpression mediates cellular radioresistance and local breast cancer recurrence after lumpectomy and radiation. Cancer Res 1997, 57:3079-3083.

12. Wolff AC, Hammond ME, Schwartz JN, Hagerty KL, Allred DC, Cote RJ, Dowsett M, Fitzgibbons PL, Hanna WM, Langer A, McShane LM, Paik S, Pegram MD, Perez EA, Press MF, Rhodes A, Sturgeon C, Taube SE, Tubbs R, Vance $\mathrm{GH}$, van de Vijver M, Wheeler TM, Hayes DF, American Society of Clinical Oncology/College of American Pathologists: American Society of Clinical Oncology/College of American Pathologists guideline recommendations for human epidermal growth factor receptor 2 testing in breast cancer. J Clin Oncol 2007, 25:118-145.

13. Antonelli M, Massimino M, Morra I, Garre ML, Gardiman MP, Buttarelli FR, Arcella A, Giangaspero F: Expression of pERK and pAKT in pediatric high grade astrocytomas: correlation with YKL40 and prognostic significance. Neuropathology 2012, 32:133-138.

14. Chen S, Chen CM, Yu KD, Yang WT, Shao ZM: A prognostic model to predict outcome of patients failing to achieve pathological complete response after anthracycline-containing neoadjuvant chemotherapy for breast cancer. J Surg Oncol 2012, 105:577-585.

15. Taunk NK, Goyal S, Moran MS, Yang Q, Parikh R, Haffty BG: Prognostic significance of IGF-1R expression in patients treated with breast-conserving surgery and radiation therapy. Radiother Oncol 2010, 96:204-208.

16. Sangale Z, Prass C, Carlson A, Tikishvili E, Degrado J, Lanchbury J, Stone S: A robust immunohistochemical assay for detecting PTEN expression in human tumors. Appl Immunohistochem Mol Morphol 2011, 19:173-183.

17. Von Minckwitz G, Loibl S, Untch M: What is the current standard of care for anti-HER2 neoadjuvant therapy in breast cancer? Oncology 2012, 26:20-26.

18. Gori S, Sidoni A, Colozza M, Ferri I, Mameli MG, Fenocchio D, Stocchi L Foglietta J, Ludovini V, Minenza E, De Angelis V, Crinò L: EGFR, pMAPK, pAkt and PTEN status by immunohistochemistry: correlation with clinical outcome in HER2-positive metastatic breast cancer patients treated with trastuzumab. Ann Oncol 2009, 20:648-654

19. Andre F, Nahta R, Conforti R, Boulet T, Aziz M, Yuan LX, Meslin F, Spielmann M, Tomasic G, Pusztai L, Hortobagyi GN, Michiels S, Delaloge S, Esteva FJ: Expression patterns and predictive value of phosphorylated AKT in early-stage breast cancer. Ann Oncol 2008, 19:315-320.

20. Gallardo A, Lerma E, Escuin D, Tibau A, Muñoz J, Ojeda B, Barnadas A, Adrover E, Sánchez-Tejada L, Giner D, Ortiz-Martínez F, Peiró G: Increased signalling of EGFR and IGF1R, and deregulation of PTEN/PI3K/Akt pathway are related with trastuzumab resistance in HER2 breast carcinomas. Br J Cancer 2012, 106:1367-1373.
21. Derin D, Eralp Y, Ozluk Y, Yavuz E, Guney N, Saip P, Igci A, Ozmen V, Kücücük S, Aslay I, Aydiner A, Topuz E: Lower level of MAPK expression is associated with anthracycline resistance and decreased survival in patients with hormone receptor negative breast cancer. Cancer Invest 2008, 26:671-679.

22. Liedtke C, Cardone L, Tordai A, Yan K, Gomez HL, Figureoa L, Hubbard RE, Valero V, Souchon EA, Symmans WF, Hortobagyi GN, Bardelli A, Pusztai L: PIK3CA-activating mutations and chemotherapy sensitivity in stage II-III breast cancer. Breast Cancer Res 2008, 10:R27.

23. Stemke-Hale K, Gonzalez-Angulo AM, Lluch A, Neve RM, Kuo WL, Davies M, Carey M, Hu Z, Guan Y, Sahin A, Symmans WF, Pusztai L, Nolden LK, Horlings H, Berns K, Hung MC, van de Vijver MJ, Valero V, Gray JW, Bernards $R$, Mills $G B$, Hennessy $B T$ : An integrative genomic and proteomic analysis of PIK3CA, PTEN, and AKT mutations in breast cancer. Cancer Res 2008, 68:6084-6091.

24. Gagnon V, Van Themsche C, Turner S, Leblanc V, Asselin E: Akt and XIAP regulate the sensitivity of human uterine cancer cells to cisplatin, doxorubicin and taxol. Apoptosis 2008, 13:259-271.

25. Adeyinka A, Nui Y, Cherlet T, Snell L, Watson PH, Murphy LC: Activated mitogen-activated protein kinase expression during human breast tumorigenesis and breast cancer progression. Clin Cancer Res 2002, 8:1747-1753.

26. Bartholomeusz C, Gonzalez-Angulo AM, Liu P, Hayashi N, Lluch A, Ferrer-Lozano J, Hortobagyi GN: High ERK protein expression levels correlate with shorter survival in triple-negative breast cancer patients. Oncologist 2012, 17:766-774.

27. McCubrey JA, Steelman LS, Abrams SL, Lee JT, Chang F, Bertrand FE, Navolanic PM, Terrian DM, Franklin RA, D'Assoro AB, Salisbury JL, Mazzarino MC, Stivala F, Libra M: Roles of the RAF/MEK/ERK and PI3K/PTEN/AKT pathways in malignant transformation and drug resistance. Adv Enzyme Regul 2006, 46:249-279.

28. Jones RL, Salter J, A'Hern R, Nerurkar A, Parton M, Reis-Filho JS, Smith IE, Dowsett M: The prognostic significance of Ki67 before and after neoadjuvant chemotherapy in breast cancer. Breast Cancer Res Treat 2009, 116:53-68.

29. Tanei T, Shimomura A, Shimazu K, Nakayama T, Kim SJ, Iwamoto T, Tamaki $Y$, Noguchi S: Prognostic significance of Ki67 index after neoadjuvant chemotherapy in breast cancer. Eur J Surg Oncol 2011, 37:155-161.

30. Fasching PA, Heusinger K, Haeberle L, Niklos M, Hein A, Bayer CM, Rauh C, Schulz-Wendtland R, Bani MR, Schrauder M, Kahmann L, Lux MP, Strehl JD, Hartmann A, Dimmler A, Beckmann MW, Wachter DL: Ki67, chemotherapy response, and prognosis in breast cancer patients receiving neoadjuvant treatment. BMC Cancer 2011, 11:486.

doi:10.1186/1477-7819-11-307

Cite this article as: Huang et al:: Prognostic and predictive value of Phospho-p44/42 and pAKT in HER2-positive locally advanced breast cancer patients treated with anthracycline-based neoadjuvant chemotherapy. World Journal of Surgical Oncology 2013 11:307.

\section{Submit your next manuscript to BioMed Central and take full advantage of:}

- Convenient online submission

- Thorough peer review

- No space constraints or color figure charges

- Immediate publication on acceptance

- Inclusion in PubMed, CAS, Scopus and Google Scholar

- Research which is freely available for redistribution 